\title{
Human papillomavirus genotypes and the risk factors associated with multicentric intraepithelial lesions of the lower genital tract: a retrospective study
}

Jing Zhang ${ }^{1}$, Guangcong Liu' ${ }^{2}$, Xiaoli Cui ${ }^{1}$, Huihui $\mathrm{Yu}^{3}$ and Danbo Wang ${ }^{1 *}$

\begin{abstract}
Background: Multicentric intraepithelial lesions of the lower genital tract (multicentric lesions) were defined as intraepithelial lesions of two or three sites within cervix, vagina, and vulva occurring synchronously or sequentially. The characteristics of multicentric lesions has been poorly understood. This study aimed to evaluate the risk factors for multicentric lesions, including specific HPV genotypes.

Methods: A retrospective case-control study was performed involving patients histologically diagnosed with multicentric lesions between January 2018 and October 2019. Controls were patients histologically diagnosed with single cervical intraepithelial neoplasia (CIN) and admitted during the same period. Univariable and multivariable analyses were used to assess the risk factors for multicentric lesions.

Results: Of 307 patients with multicentric lesions, the median age was 50 years (interquartile range: 43-55.5), and they were older than patients with single CIN (median age: 43 years, interquartile range: $36-50$ ). In the multicentric lesion group, the proportions of cytologic abnormalities, HPV positivity, and multiple HPV infections were 68.9, 97.0, and $36.5 \%$, respectively. In the multivariable analysis, menopause, a history of malignant tumors beyond the lower genital tract and multiple HPV infections were associated with the incidence of multicentric lesions (Odd ratio $(O R)=3.14,95 \%$ confidence interval $(C l) 2.24-4.41 ; O R=9.58,95 \% \mathrm{Cl} 1.02-89.84 ; \mathrm{OR}=1.47,95 \% \mathrm{Cl} 1.03-2.10)$. The common HPV genotypes were HPV16, HPV53, HPV58, HPV52, HPV51, HPV56 and HPV18 in patients with multicentric lesions. The proportion of HPV16 infection was higher in high-grade lesions group than that in low-grade lesions group ( $\mathrm{OR}=2.54,95 \% \mathrm{Cl} 1.34-4.83$ ). The $\mathrm{OR}$ for multicentric lesions, adjusted for menopause, smoking, gravidity, parity, a history of malignant tumor beyond the lower genital tract and multiple HPV infection, was $1.97(95 \% \mathrm{Cl}$ 1.04-3.75) in patients with HPV51 infection.
\end{abstract}

Conclusions: Multicentric lesions were associated with menopause, a history of malignant tumors and multiple HPV infections. HPV16 was the most common genotype, especially in high grade multicentric lesions and HPV51 infection was found to be a risk factor for detecting multicentric lesions.

Keywords: Multicentric intraepithelial lesions, Human papillomavirus, Genotypes, Prevalence, Risk factors

\footnotetext{
* Correspondence: wangdanbo@cancerhosp-In-cmu.com

'Department of Gynecology, Cancer Hospital of China Medical University,

Liaoning Cancer Hospital and Institute, No.44 Xiaoheyan Road, Shenyang

110042, Liaoning province, China

Full list of author information is available at the end of the article
}

(c) The Author(s). 2021 Open Access This article is licensed under a Creative Commons Attribution 4.0 International License, which permits use, sharing, adaptation, distribution and reproduction in any medium or format, as long as you give appropriate credit to the original author(s) and the source, provide a link to the Creative Commons licence, and indicate if changes were made. The images or other third party material in this article are included in the article's Creative Commons licence, unless indicated otherwise in a credit line to the material. If material is not included in the article's Creative Commons licence and your intended use is not permitted by statutory regulation or exceeds the permitted use, you will need to obtain permission directly from the copyright holder. To view a copy of this licence, visit http://creativecommons.org/licenses/by/4.0/ The Creative Commons Public Domain Dedication waiver (http://creativecommons.org/publicdomain/zero/1.0/) applies to the data made available in this article, unless otherwise stated in a credit line to the data. 


\section{Background}

Persistent human papillomavirus (HPV) infections play a critical role in the development of lower genital tract precancerous and cancerous diseases. Cervical intraepithelial neoplasia (CIN) is common with an incidence that is ten times higher than that of vaginal intraepithelial neoplasia (VAIN) or vulvar intraepithelial neoplasia (VIN). However, the incidence of VAIN or VIN has increased recently [1]. In 1960, Marcus et al. [2] first described the theory of multicentric origin in lower genital tract. Multicentric intraepithelial lesions of the lower genital tract (referred to as multicentric lesions) were defined as those occurring in two or three sites within the cervix, vagina, and vulva, which could occur synchronously or sequentially [3]. Multicentric lesions can occur sequentially but be detected at the same clinical visit [4]. Multicentric lesions were significantly more likely to be detected synchronously than sequentially [5].

A comprehensive diagnosis of multicentric lesions can be challenging, as vaginal or vulvar lesions are easily missed on clinical exam; these missed diagnoses lead to a poor prognosis. Previous studies have found that multicentric lesions are a risk factor for residual lesion and disease recurrence $[3,6,7]$. At present, there are few articles which describing the characteristics and significance of multicentric intraepithelial lesions. and the sample sizes of the previous studies have been small [3-5]. Moreover, HPV testing is useful for the detection of multicentric lesions, however, available data about the HPV genotypes prevalence in multicentric lesions are limited.

Therefore, in this study, we aimed to describe the clinical characteristics of a large number of patients with multicentric intraepithelial lesions of the lower genital tract which were detected synchronously. We also examined the prevalence of different HPV genotypes. Correlations between several risk factors and the incidence of multicentric lesions were also assessed.

\section{Methods}

\section{Study population}

A retrospective case-control study was conducted with patients undergoing colposcopy-guided biopsy at the Cervical Disease Clinic of Liaoning Cancer Hospital and Institute, which serves as a referral center in northeastern China. Patients with a histologically confirmed diagnosis of multicentric lesions detected synchronously (CIN with VAIN and/or VIN, VAIN with VIN), between January 1st, 2018, and October 31st, 2019, were included in the study and were placed into the multicentric lesions group. Moreover, we enrolled patients with histologically confirmed diagnoses of single $\mathrm{CIN}$, who were admitted during the same period to be in the single CIN control group. Exclusion criteria were the presence of concurrent invasive cancer in the lower genital tract, a history of invasive cancer in the lower genital tract, multicentric lesions detected sequentially or pregnancy. In the multicentric group, two subgroups were divided according to the grade of CIN, including high-grade lesions group (CIN2+ with VAIN and/or VIN) and lowgrade lesions group (CIN1 with VAIN and/or VIN).

\section{Clinical data}

Clinical data were retrieved retrospectively from electronic medical records and picture archiving and communication systems (PACS) in the hospital by trained gynecological staff using standardized data collection and quality control procedures, including demographic details, menopause status, symptoms, a history of other diseases, cytology results (identified with ThinPrep liquid-based cytology system, Hologic Inc., MA, USA), HPV infection and genotypes, high-risk HPV (HR-HPV) viral loads and histopathologic results.

HR-HPV DNA viral loads were detected using the Digene Hybrid Capture 2 (HC2) test (Digene Co., MD, USA). HPV DNA was detected and genotyped with the HPV GenoArray test kit (Hybribio Ltd., Hong Kong) using both DNA amplification and a flow-through hybridization technique [8]. A total of 21 genotypes were screened, including13 high-risk genotypes (HPV16, HPV18, HPV31, HPV33, HPV35, HPV39, HPV45, HPV51, HPV52, HPV56, HPV58, HPV59, and HPV68), two probable high-risk genotypes (HPV53 and HPV66) and six low-risk genotypes (HPV6, HPV11, HPV42, HPV43, HPV44, and CP8304).

Colposcopy was performed in the Cervical Disease Clinic of our hospital. Women were referred to colposcopy if cytologic result was low-grade squamous intraepithelial lesion (LSIL) or worse, or cytologic result was atypical squamous cell of unknown significance (ASCU S) companied with HPV infection, or HPV16/18 were positive with normal cytology, or other HR-HPV genotype infection persists 6 months with normal cytology. Comprehensive assessments of the cervix, vagina, and vulva were carried out. Colposcopy-guided biopsies were performed if suspicious lesions were found. Biopsy tissue sections were independently assessed by two expert pathologists.

\section{Statistical analyses}

Normality of continuous variables was determined using the Kolmogorov-Smirnov test. When data were continuously and normally distributed, quantitative variables were presented as the mean \pm standard deviation (SD), and the Student's $t$-test was used to compare differences. When data were abnormally distributed, quantitative variables were presented as the Median and Interquartile range (IQR), and the Mann-Whitney $U$ test was used to compare differences. Univariable analyses were performed to 
quantify the association between independent variables and binary outcomes using logistic regression analyses for categorical variables. The multiple logistic regression model was used to quantify independent factors associated with multicentric lesions. The prevalence of HPV was expressed as the proportion of HPV-positive cases compared with the total number of HPV cases. Logistic regression analyses, which were adjusted for menopause, a history of malignant tumors, and multiple HPV infections, were used to estimate correlations between specific HRHPV genotypes and the number of multicentric lesions detected, and the Odds ratios (ORs) with 95\% confidence intervals (CIs) were calculated. Data were analyzed using the SPSS version 22.0 software (SPSS Inc., Chicago, IL, USA).

This study was approved by the ethical committee of Liaoning Cancer Hospital and Institute (reference number 2020-0610); this approval allowed access to the data used for this research.

\section{Results}

\section{Clinical characteristics}

A total of 1950 patients were enrolled, including 307 patients in the multicentric lesions group and 1643 patients in the single CIN group (Fig. 1). The clinical characteristics of the two groups are presented in Table 1. The median age of the multicentric lesions group was higher than that of the single CIN group (50 years, interquartile range 43-55.5; 43 years, interquartile range $36-50$, respectively). In the multicentric lesions group, 279 patients $(279 / 307,90.9 \%)$ were asymptomatic. In addition, nine patients had postcoital bleeding, 8 patients had abnormal vaginal bleeding, 5 patients had vulvar itching, 5 patients had increased vaginal discharge and 1 patient had bleeding after menopause. In the multicentric lesions group, 13 patients had a history of other diseases ( 6 cases with breast cancer, one case with lung cancer, one case with lymphoma, one case with thyroid cancer, one case with endometrial cancer, one case with thrombocytopenia, one case with depression and one case with hypothyroidism). Ten (3.3\%) patients had a history of malignant tumor beyond lower genital tract.

Cytologic results were available for 267 patients in the multicentric lesions group and 1332 patients in the single CIN group. Among them, 184 (68.9\%) patients in the multicentric lesions group and $833(62.5 \%)$ patients in the single CIN group had abnormal cytologic results, such as atypical squamous cell with unknown sense or worse (Table 1).

HPV status was available in 303 patients in the multicentric lesions group. Patients in the multicentric lesions group as compared to controls were more likely to be HPV positive (OR $=2.07,95 \%$ CI $1.03-4.15)$. HR-HPV viral loads were available for 102 patients in the multicentric lesions group. The median relative light units over a positive control-derived cutoff value (RLU/ $\mathrm{CO}$ ) was 272.165 with an interquartile range (IQR) of 1118.17, which was higher than that in the single CIN group (10.13 RLU/CO, IQR:16.70) (Table 1).

\section{The prevalence of the HPV genotypes}

In the multicentric lesions group, HPV genotype results were available for 177 patients. Multiple HPV infections were identified in $65 / 178,36.5 \%$. One patient in the multicentric lesions group and five patients in the single CIN group was recorded to have multiple HPV infection, but their HPV genotyping results were unavailable. The proportion of patients with multiple HPV infections in the multicentric lesions group was higher than in the single CIN group (OR $=1.54,95 \% \mathrm{CI} 1.09-2.17$ ) (Table 1). The prevalence of HPV genotypes in the multicentric lesions and single CIN groups are shown in Table 2. HPV16 was the most common genotype in both groups. In the multicentric lesions group, HPV53 (24, 13.6\%) ranked second, followed by HPV58 (22, 12.4\%), HPV52 (19, 10.7\%), HPV51 (17, 9.6\%), HPV56 (17, 9.6\%), and HPV18 (16, 9.0\%). However, HPV52 ranked second in the single CIN group, whereas HPV18 ranked fourth, and HPV53 dropped to the sixth most common in this group. There were low-risk genotype infections in both groups. The common genotypes were HPV43, HPV81, HPV42, and HPV6. However, the low-risk genotypes were always present with high-risk genotypes as coinfections. Only two patients had HPV43 single infections in the multicentric lesions group.

\section{Comparison between two subgroups of the multicentric lesion group}

The median age of patient in both subgroups was similar (Low-grade lesions group median age: 50 years, Q1-Q3: 43-56; High-grade lesions group median age: 50 years, Q1-Q3: 41.5-55). If the cervical intraepithelial lesions were high grade, combined vaginal or vulvar intraepithelial lesions was more likely to be high grade $(\mathrm{OR}=2.82$, 95\%CI 1.68-4.73). Compared to low-grade lesions group, HPV16 infection was more popular in high-grade lesions group $(\mathrm{OR}=2.54,95 \% \mathrm{CI} 1.34-4.83)$. However, the proportions of HPV18 infection in both subgroups was similar $(\mathrm{OR}=1.78,95 \% \mathrm{CI} 0.61-5.28)$. In the lowgrade lesions group, non HPV16/18 infections were more popular than that in high-grade lesions group $(\mathrm{OR}=3.04,95 \% \mathrm{CI} 1.59-5.82)$ (Table 3$)$.

\section{Risk factors associated with multicentric lesions}

In the univariable analysis (Table 1), multicentric lesions were found to be associated with several factors, including menopause ( $\mathrm{OR}=2.73,95 \%$ CI $2.13-3.50)$, a history of malignant tumors beyond the lower genital tract 


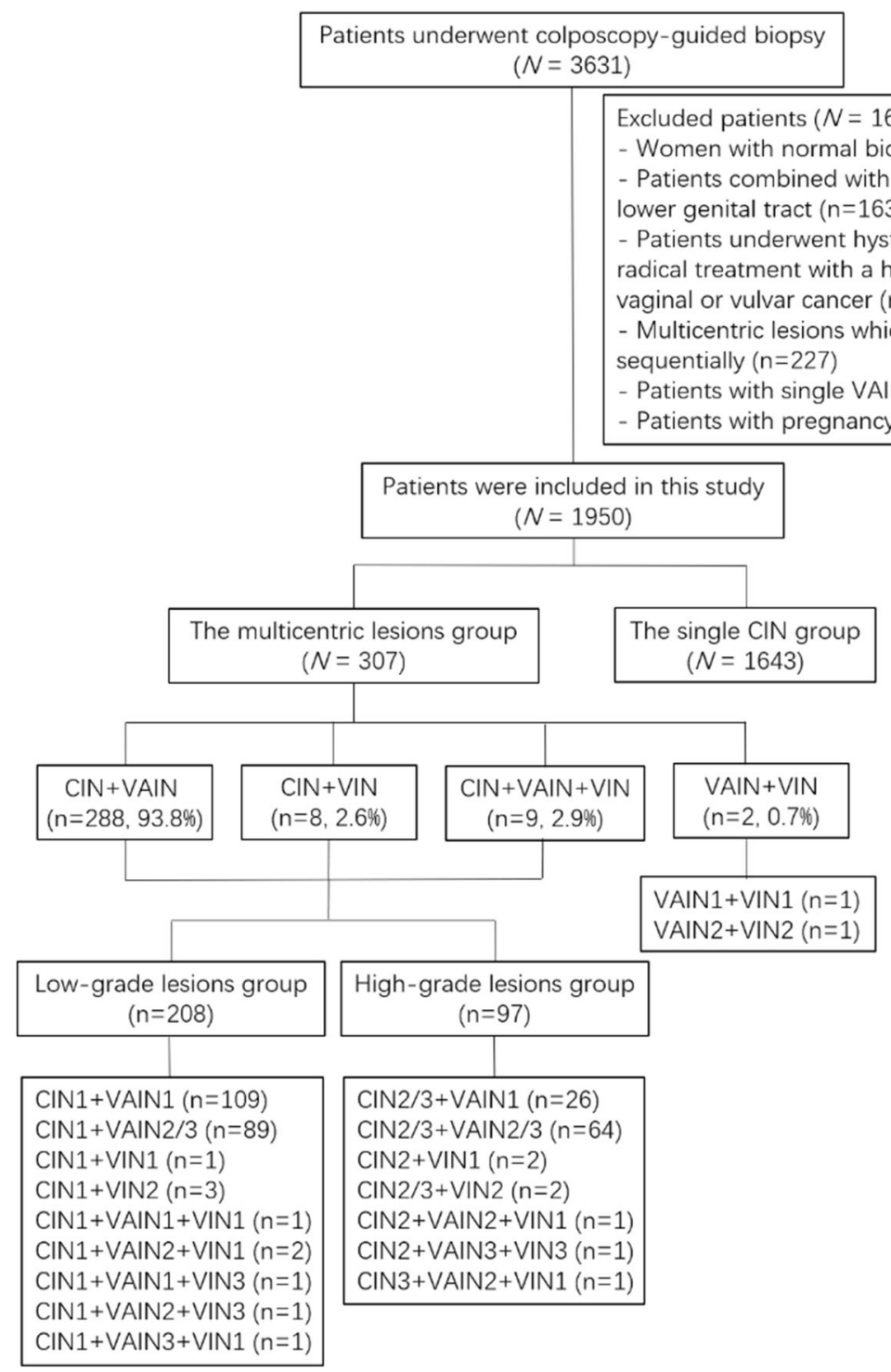

Fig. 1 Flow diagram of the study population. (CIN, cenvical intraepithelial neoplasia; VAIN, vaginal intraepithelial neoplasia; VIN, vulvar intraepithelial neoplasia)

$(\mathrm{OR}=5.05,95 \%$ CI 2.21-11.55), multiple HPV infections $(\mathrm{OR}=1.54,95 \% \mathrm{CI} 1.09-2.17)$ and HR-HPV viral loads $>1000 \mathrm{RLU} / \mathrm{CO}(\mathrm{OR}=1.76,95 \%$ CI 1.05-2.95).

In the multivariable analysis (Table 1), menopause (OR $=3.14,95 \%$ CI 2.24-4.41), a history of malignant tumors $(\mathrm{OR}=9.58,95 \%$ CI 1.02-89.84) and multiple HPV infections $(\mathrm{OR}=1.47,95 \% \mathrm{CI} 1.03-2.10)$ were found to be independent risk factors for multicentric lesions.

Correlations among the top seven common HR-HPV genotypes and multicentric lesions detection are shown in Table 4. Of the 52 patients with HPV51 infection, 17 patients $(32.7 \%)$ were diagnosed with multicentric lesions on histopathology. The risk of detecting multicentric lesions in patients with HPV51 infections was 2.37 times greater than detecting them in patients with
non-HPV51 infections (OR $=2.37$, 95\% CI 1.29-4.33). Accordingly, HPV53 and HPV56 infections were correlated with multicentric tumor detection $(\mathrm{OR}=2.35,95 \%$ CI 1.40-3.93; OR $=1.82,95 \%$ CI 1.01-3.26, respectively). After adjusting for menopause, smoking, Gravidity, Parity, A history of malignant tumor beyond the lower genital tract and multiple HPV infection, only HPV51 infection was correlated with multicentric lesion detection $(\mathrm{OR}=1.97$, 95\% CI 1.04-3.75).

\section{Discussion}

In this retrospective case-control study, it was indicated that the risk factors for multicentric lesions included menopause, a history of malignant tumors beyond the lower genital tract and multiple HPV infections using 


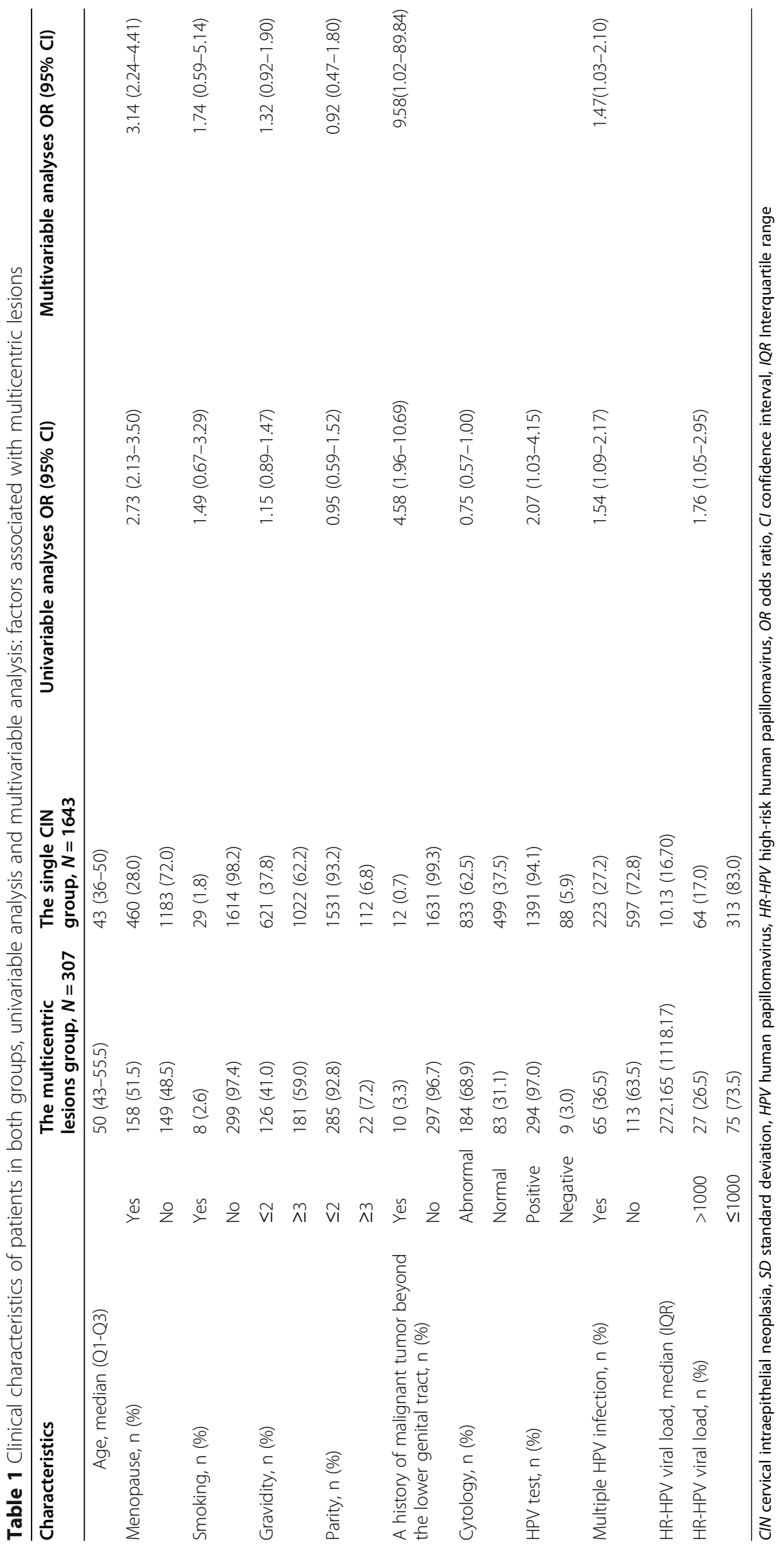


Table 2 The prevalence of HPV genotypes in patients of both

\begin{tabular}{|c|c|c|}
\hline HPV genotypes & $\begin{array}{l}\text { The multicentric } \\
\text { lesions group }(n=177)\end{array}$ & $\begin{array}{l}\text { The single CIN group } \\
(n=815)\end{array}$ \\
\hline \multicolumn{3}{|c|}{ High-risk genotypes, n (\%) } \\
\hline 16 & 69(39.0) & $338(41.5)$ \\
\hline 18 & $16(9.0)$ & $68(8.3)$ \\
\hline 31 & $11(6.2)$ & $51(6.3)$ \\
\hline 33 & $15(8.5)$ & $60(7.4)$ \\
\hline 35 & $3(1.7)$ & $24(2.9)$ \\
\hline 39 & $3(1.7)$ & $34(4.2)$ \\
\hline 45 & $6(3.4)$ & $6(0.7)$ \\
\hline 51 & 17(9.6) & $35(4.3)$ \\
\hline 52 & 19(10.7) & $123(15.1)$ \\
\hline 53 & 24(13.6) & $51(6.3)$ \\
\hline 56 & $17(9.6)$ & $45(5.5)$ \\
\hline 58 & $22(12.4)$ & $115(14.1)$ \\
\hline 59 & $6(3.4)$ & $23(2.8)$ \\
\hline 66 & $4(2.3)$ & 29(3.6) \\
\hline 68 & $9(5.1)$ & $41(5.0)$ \\
\hline \multicolumn{3}{|c|}{ Low-risk genotypes, n (\%) } \\
\hline 6 & $5(2.8)$ & $10(1.2)$ \\
\hline 11 & $3(1.7)$ & $1(0.1)$ \\
\hline 42 & $5(2.8)$ & $20(2.5)$ \\
\hline 43 & $7(4.0)$ & $10(1.2)$ \\
\hline 44 & $1(0.6)$ & $2(0.2)$ \\
\hline 81 & $6(3.4)$ & $19(2.3)$ \\
\hline
\end{tabular}

Note: Women with multiple HPV types detected are counted to each type, and therefore counted more than once

HPV human papillomavirus, CIN cervical intraepithelial neoplasia

the multivariable analyses. In the multicentric lesions group, the top seven common HPV genotypes were HPV16, HPV53, HPV58, HPV52, HPV51, HPV56 and HPV18. The risk of detecting multicentric lesions in patients with HPV51 infection was 1.97 times of that in patients with non-HPV51 infection adjusted for menopause, smoking, gravidity, parity, a history of malignant tumor beyond the lower genital tract and multiple HPV infection.

With the advancement of cervical cancer screening, and the standardization of the colposcopy procedure, the detection rate of vaginal or vulva intraepithelial neoplasia has gradually increased [9-11]. The incidence of multicentric lesions has been reported in only $4.4 \%$ of patients with CIN [3]. In recent years, $\mathrm{He} \mathrm{Y}$ et al. conducted a prospective cohort study and reported that $19.4 \%$ of CIN patients had CIN combined with VAIN [12]. In this study, the proportion of patients with multicentric lesions detected synchronously were $15.7 \%$. Thus, the incidence of multicentric lesions is increasing.
Therefore, physicians should be aware that a patient with HPV infection could present with multicentric lesions.

The average age of patients with multicentric lesions has not been consistent in previous studies, ranged from 36.3 to 43 years $[3-5,13]$. In this study, the median age of patients with multicentric lesions was higher than that reported in the previous literatures. This phenomenon might be due to different sample sizes, populations, or other factors. He Y et al. [12] reported that the occurrence of CIN with VAIN was increasing with the increase of age. Moreover, menopause was an independent risk factor for multicentric lesions in this study. On one hand, the average age of patients with VAIN or VIN reported in the literatures has generally been older than that of CIN patients [14-16]. On the other hand, perimenopausal period is one of the two infection peaks of HR-HPV $[17,18]$. Due to the decrease of estrogen level, the vaginal epithelium becomes thinner and more prone to microscopic damage. Moreover, hormone fluctuations can cause immune system regulation disturbances, such as the level of IL-6 increasing and Th1 / Th2 balance shifting to Th1 $[19,20]$. So, the elimination or inhibition of HPV infection is weakened during menopause or perimenopause [21].

Most patients with multicentric lesions had no clinical symptoms. VAIN mostly involved the fornix and the upper third of vagina, high-grade lesions even involved the whole vagina. The images of VAIN under colposcopy were mainly micropapillary hyperplasia, acetic acid white epithelium, punctate blood vessels and Lugol's iodine non-coloring [11]. Frega et al. [5] compared patients with multicentric lesions detected synchronously with those detected sequentially, and found a significant correlation between immunosuppression and synchronously detected multicentric lesions. Hammer A et al. [22] provided molecular evidence of HPV latency in humans. And, immunosuppression can trigger the reactivation of latent papillomavirus genomes [23]. Moreover, in this study, a history of malignant tumor was a risk factor for multicentric lesions. Although the mechanism is still unclear, the immunity of patient with a history of malignant tumor might be suppressed due to the stress after surgery and the side effects of radiotherapy or chemotherapy.

Multicentric lesions development is closely related to HR-HPV infection in the lower genital tract; however, the pathogenesis is not completely clear. So far, there are three theories to the pathogenesis. First, one persistent infection with a certain HPV genotype could induce the development of several independent lesions, representing synchronous multicentric lesion development, where there are either high viral loads or a high-risk for transformation. Second, repeated independent infections 
Table 3 Comparison between two subgroups of the multicentric lesion group

\begin{tabular}{|c|c|c|c|c|}
\hline & & $\begin{array}{l}\text { Low-grade lesions group, } n= \\
208(\%)\end{array}$ & $\begin{array}{l}\text { High-grade lesions group, } n= \\
97,(\%)\end{array}$ & OR(95\% Cl) \\
\hline Age, median (Q1-Q3) & & $50(43-56)$ & $50(41.5-55)$ & \\
\hline \multirow[t]{2}{*}{$\begin{array}{l}\text { The grade of vaginal and/or vulval lesion, } n \\
(\%)\end{array}$} & VAIN1NIN1 & 111(53.4) & 28(28.9) & $\begin{array}{l}2.82(1.68- \\
4.73)\end{array}$ \\
\hline & VAIN2-3/NIN2 & $97(46.6)$ & $69(71.1)$ & \\
\hline \multirow[t]{2}{*}{ HPV test, n (\%) } & Positive & 198(95.7) & $94(100)$ & NA \\
\hline & Negative & $9(4.3)$ & 0 & \\
\hline \multirow[t]{2}{*}{ Multiple HPV infection, n (\%) } & Yes & $43(37.1)$ & $20(33.3)$ & $\begin{array}{l}0.85(0.44- \\
1.64)\end{array}$ \\
\hline & No & $73(62.9)$ & $40(66.7)$ & \\
\hline \multirow[t]{2}{*}{ HR-HPV viral load, n (\%) } & $>1000$ & 19(26.8) & $8(27.6)$ & $\begin{array}{l}0.96(0.36- \\
2.53)\end{array}$ \\
\hline & $\leq 1000$ & $52(73.2)$ & $21(72.4)$ & \\
\hline $\begin{array}{l}\text { No. of patients with available HPV genotype } \\
\text { results, } n\end{array}$ & & 115 & 60 & \\
\hline \multirow[t]{3}{*}{ HR-HPV genotype, n (\%) } & 16 & $36(31.3)^{a}$ & $32(53.3)$ & $\begin{array}{l}2.54(1.34- \\
4.83)\end{array}$ \\
\hline & 18 & $8(7.0)$ & $7(11.7)$ & $\begin{array}{l}1.78(0.61- \\
5.28)\end{array}$ \\
\hline & $\begin{array}{l}\text { Non } 16 / 18 \\
\text { genotypes }\end{array}$ & $72(62.6)$ & $21(35.0)$ & $\begin{array}{l}3.04(1.59- \\
5.82)\end{array}$ \\
\hline
\end{tabular}

a one patient had both HPV16 and HPV18 infection

$H P V$ human papillomavirus, HR-HPV high-risk human papillomavirus, $\mathrm{OR}$ odds ratio, $\mathrm{Cl}$ confidence interval

with various HPV genotypes can induce independent lesions $[1,4]$. Third, precancerous cell clones can spread in the lower genital tract and induce lesions occurring sequentially [2]. The detection of identical HPV integration sites supported this mechanism of clonally related lesions. Consistent with the first pathogenesis theory, in this study, the median HR-HPV viral load was significantly higher in the multicentric lesions group than in the single CIN group, and HR-HPV viral loads $>1000$ RLU/CO were correlated with multicentric lesions with the univariable analysis. In addition, in high-grade lesions subgroup, more than half (53.3\%) of the patients were HPV16 infection. Consistent with the second pathogenesis theory and previous study [5], in this study, multiple HPV infections were an independent risk factor for multicentric lesions. However, multiple HPV infections did not significantly increase the risk of high-grade lesion beyond that for the highest-risk type found [24]. In this study, the proportions of multiple HPV infections in both subgroups were similar.

The prevalence of HPV genotypes would be useful for the development of screening and management guidelines for multicentric lesions. In this study, HPV16 was also the most common genotype, especially in highgrade lesions subgroup; HPV53, HPV58, HPV52, HPV51 and HPV56 were all more common than HPV18. Similar

Table 4 The correlation between the top seven common high-risk HPV genotypes and multicentric lesions detection

\begin{tabular}{llll}
\hline HPV genotypes & $\begin{array}{l}\text { No. of multicentric } \\
\text { lesions, } \boldsymbol{n}(\%)\end{array}$ & $\begin{array}{l}\text { Univariable } \\
\text { analysis } \\
\text { OR (95\% Cl) }\end{array}$ & $\begin{array}{l}\text { Adjusting for menopause, smoking, } \\
\text { gravidity and etc. * OR (95\% Cl) }\end{array}$ \\
\hline HPV16, $n=407$ & $69(17.0)$ & $0.90(0.65-1.26)$ & $0.93(0.66-1.31)$ \\
HPV53, $n=75$ & $24(32.0)$ & $2.35(1.40-3.93)$ & $1.61(0.92-2.81)$ \\
HPV58, $n=137$ & $22(16.1)$ & $0.86(0.53-1.41)$ & $0.83(0.50-1.39)$ \\
HPV52, $n=142$ & $19(13.4)$ & $0.68(0.41-1.13)$ & $0.56(0.32-0.97)$ \\
HPV51, $n=52$ & $17(32.7)$ & $2.37(1.29-4.33)$ & $1.97(1.04-3.75)$ \\
HPV56, $n=62$ & $17(27.4)$ & $1.82(1.01-3.26)$ & $1.59(0.85-2.98)$ \\
HPV18, $n=84$ & $16(19.0)$ & $1.09(0.62-1.93)$ & $1.09(0.60-1.98)$ \\
\hline
\end{tabular}

* adjusted for menopause, smoking, gravidity, parity, a history of malignant tumor beyond the lower genital tract and multiple HPV infection HPV, human papillomavirus 
findings have previously been reported. HPV18 was rare in Asian patients with VAIN [25]. A Japanese study reported HPV52, 16, 51, 53 and 56 were the most common types in patients with VAIN [26]. However, an Italian study [5] reported that the top four common HPV genotypes associated with multicentric lesions were HPV16, HPV18, HPV33 and HPV31. A study from 31 countries showed HPV18 was the second common genotype in VAIN2/3 [27]. The possible reasons for these inconsistencies are regional differences, different detection methods, different sample sizes. In this study, HPV53, HPV51, and HPV56 were more common in patients of the multicentric lesion group compared with those of the single CIN group. HPV51, HPV53 and HPV56 infections were correlated with multicentric lesion detection using logistic regression analyses. After adjusting for menopause status, a history of malignant tumors, and multiple HPV infections, only HPV51 infections were found to be a risk factor for multicentric lesion detection. Thus, we should be alert to the occurrence of multicentric lesions in patients with HPV51 infection. However, HPV51 pathogenesis needs to be further studied.

\section{Strengths and limitations of the study}

This study was done in relatively higher sample size with appropriate analysis technique that provides important information regarding HPV genotypes prevalence and risk factors associated with multicentric lesions in northeastern China. However, this study had some limitations. First, the retrospective design of this study could miss some variables in the analysis such as data related to oral contraceptives and number of sexual partners. Second, the number of patients that had HPV genotyping performed was relatively limited. Hence, more studies, specifically large prospective studies, are required.

\section{Conclusions}

Currently, the incidence of multicentric lesions is increasing. Multicentric lesions were closely related to menopause, a history of malignant tumors beyond the lower genital tract and multiple HPV infections. The common HPV genotypes were HPV16, HPV53, HPV58, HPV52, HPV51, HPV56 and HPV18. HPV51 infection was a risk factor for multicentric lesions detection. To avoid missing a diagnosis of multicentric lesions, comprehensive colposcopical evaluations of the cervix, vagina, and vulva is warranted especially in women with risk factors.

\section{Abbreviations}

CIN: cervical intraepithelial neoplasia; VAIN: vaginal intraepithelial neoplasia; VIN: vulvar intraepithelial neoplasia; HPV: human papillomavirus; HR-

HPV: high-risk human papillomavirus; OR: odds ratio; Cl: confidence interval

\section{Acknowledgements}

The authors would like to thank Xin Yao and Yumei Xiu for their excellent assistance in data management.

\section{Authors' contributions}

JZ and DBW was responsible for conception, design and quality control of this study. JZ wrote the main manuscript text. JZ, GCL and HHY participated in statistical analysis and prepared tables and Figs. JZ and XLC involved in acquisition of data. JZ, GCL and DBW revised the manuscript. All authors read and approved the final manuscript.

\section{Funding}

This study was supported by National Key Research and Development Project "Research and Development of Digital Diagnostic and Medical Equipment" (grant number 2017YFC0114200), Liaoning Province Key Research and Development Project (grant number 2018225037). The funders had no role in study design, data collection and analysis, decision to publish, or preparation of the manuscript.

\section{Availability of data and materials}

The dataset analyzed in this study is available from the corresponding author upon reasonable request.

\section{Declarations}

\section{Ethics approval and consent to participate}

This study was reviewed and approved by the ethical committee of Liaoning Cancer Hospital and Institute (reference number 2020-0610). All the procedures have been performed in accordance with the ethical standards laid down in the 1964 Declaration of Helsinki and its later amendments. All data was anonymised and informed consent was waived from the ethics committee of Liaoning Cancer Hospital and Institute.

Consent for publication

Not applicable.

\section{Competing interests}

All authors declare there are no conflicts of interest.

\section{Author details}

'Department of Gynecology, Cancer Hospital of China Medical University, Liaoning Cancer Hospital and Institute, No.44 Xiaoheyan Road, Shenyang 110042, Liaoning province, China. ${ }^{2}$ Department of Epidemiology, Cancer Hospital of China Medical University, Liaoning Cancer Hospital and Institute, Shenyang 110042, Liaoning province, China. ${ }^{3}$ Department of Cancer Prevention and Treatment, Cancer Hospital of China Medical University, Liaoning Cancer Hospital and Institute, Shenyang 110042, Liaoning province, China.

Received: 24 January 2021 Accepted: 24 May 2021

Published online: 11 June 2021

\section{References}

1. Vinokurova S, Wentzensen $N$, Einenkel J, Klaes R, Ziegert C, Melsheimer P, et al. Clonal history of papillomavirus-induced dysplasia in the female lower genital tract. J Natl Cancer Inst. 2005;97(24):1816-21. https://doi.org/10.1093/ jnci/dji428.

2. Marcus SL. Multiple squamous cell carcinomas involving the cervix, vagina, and vulva: the theory of multicentric origin. Am J Obstet Gynecol. 1960; 80(4):802-12. https://doi.org/10.1016/0002-9378(60)90593-7.

3. Ait Menguellet $S$, Collinet $P$, Houfflin Debarge $V$, Nayama M, Vinatier $D$, Leroy JL. Management of multicentric lesions of the lower genital tract. Eur J Obstet Gynecol Reprod Biol. 2007;132(1):116-20. https://doi.org/10.1016/j. ejogrb.2006.04.011.

4. Hampl M, Wentzensen N, Vinokurova S, von Knebel-Doeberitz M, Poremba C, Bender HG, et al. Comprehensive analysis of 130 multicentric intraepithelial female lower genital tract lesions by HPV typing and p16 expression profile. J Cancer Res Clin Oncol. 2007;133(4):235-45. https://doi. org/10.1007/s00432-006-0162-0.

5. Frega A, Sesti F, Sopracordevole F, Biamonti A, Votano S, Catalano A, et al. Multiple intraepithelial neoplasias of the lower female genital tract: the 
reliability of HPV mRNA test. J Low Genit Tract Dis. 2014;18(2):174-81. https://doi.org/10.1097/LGT.0b013e31829706bc.

6. Dodge JA, Eltabbakh GH, Mount SL, Walker RP, Morgan A. Clinical features and risk of recurrence among patients with vaginal intraepithelial neoplasia. Gynecol Oncol. 2001;83(2):363-9. https://doi.org/10.1006/gyno.2001.6401.

7. Sykes P, Smith N, McCormick P, Frizelle FA. High-grade vulval intraepithelial neoplasia (VIN 3): a retrospective analysis of patient characteristics, management, outcome and relationship to squamous cell carcinoma of the vulva 1989-1999. Aust N Z J Obstet Gynaecol. 2002;42(1):69-74. https://doi. org/10.1111/j.0004-8666.2002.00075.x.

8. Liu SS, Leung RC, Chan KK, Cheung AN, Ngan HY. Evaluation of a newly developed GenoArray human papillomavirus (HPV) genotyping assay and comparison with the Roche linear Array HPV genotyping assay. J Clin Microbiol. 2010;48(3):758-64. https://doi.org/10.1128/JCM.00989-09.

9. Kurdgelashvili G, Dores GM, Srour SA, Chaturvedi AK, Huycke MM, Devesa SS. Incidence of potentially human papillomavirus-related neoplasms in the United States, 1978 to 2007. Cancer. 2013;119(12):2291-9. https://doi.org/1 $0.1002 /$ cncr.27989

10. Satmary W, Holschneider CH, Brunette LL, Natarajan S. Vulvar intraepithelia neoplasia: risk factors for recurrence. Gynecol Oncol. 2018;148(1):126-31. https://doi.org/10.1016/j.ygyno.2017.10.029.

11. Zhang J, Chang X, Qi Y, Zhang Y, Zhang S. A retrospective study of 152 women with vaginal intraepithelial neoplasia. Int J Gynaecol Obstet. 2016. 133(1):80-3. https://doi.org/10.1016/j.jjgo.2015.08.014.

12. He Y, Zhao Q, Geng YN, Yang SL, Yin CH, Wu YM. Clinical analysis of cervical intraepithelial neoplasia with vaginal intraepithelial neoplasia. Medicine (Baltimore). 2017;96(17):e6700. https://doi.org/10.1097/MD. 0000000000006700 .

13. Gonzalez-Bosquet E, Mazarico E, Lorente N, Gomez-Roig MD. Risk factors to develop multicentric lesions of the lower genital tract. Eur I Gynaecol Oncol. 2017;38(1):10-3.

14. Siegler E, Segev Y, Mackuli L, Auslender R, Shiner M, Lavie O. Vulvar and vaginal Cancer, vulvar intraepithelial neoplasia 3 and vaginal intraepithelial neoplasia 3: experience of a referral institute. Isr Med Assoc J. 2016;18(5): 286-9.

15. Gunderson CC, Nugent EK, Elfrink SH, Gold MA, Moore KN. A contemporary analysis of epidemiology and management of vaginal intraepithelial neoplasia. Am J Obstet Gynecol. 2013;208(5):410 e1-410.e4106.

16. Boonlikit S, Noinual N. Vaginal intraepithelial neoplasia: a retrospective analysis of clinical features and colpohistology. J Obstet Gynaecol Res. 2010; 36(1):94-100. https://doi.org/10.1111/j.1447-0756.2009.01108.x.

17. Sun LL, Jin Q, Li H, Zhou XR, Song ZQ, Cheng XM, et al. Population-based study on the prevalence of and risk factors for human papillomavirus infection in Qujing of Yunnan province, Southwest China. Virol J. 2012;9:153.

18. Lin M, Yang LY, Li LJ, Wu JR, Peng YP, Luo ZY. Genital human papillomavirus screening by gene chip in Chinese women of Guangdong province. Aust N Z J Obstet Gynaecol. 2008;48(2):189-94. https://doi.org/1 0.1111/j.1479-828X.2008.00844.X.

19. Berg G, Ekerfelt C, Hammar M, Lindgren R, Matthiesen L, Ernerudh J. Cytokine changes in postmenopausal women treated with estrogens: a placebo-controlled study. Am J Reprod Immunol. 2002;48(2):63-9. https:// doi.org/10.1034/j.1600-0897.2002.01061.x.

20. Salem ML. Estrogen, a double-edged sword: modulation of $\mathrm{TH} 1-$ and $\mathrm{TH} 2-$ mediated inflammations by differential regulation of $\mathrm{TH} 1 / \mathrm{TH} 2$ cytokine production. Curr Drug Targets Inflamm Allergy. 2004;3(1):97-104. https://doi. org/10.2174/1568010043483944.

21. Althoff KN, Paul P, Burke AE, Viscidi R, Sangaramoorthy M, Gravitt PE. Correlates of cervicovaginal human papillomavirus detection in perimenopausal women. J Women's Health (Larchmt). 2009;18(9):1341-6. https://doi.org/10.1089/jwh.2008.1223.

22. Hammer A, de Koning MN, Blaakaer J, Steiniche T, Doorbar J, Griffin H, et al. Whole tissue cervical mapping of HPV infection: molecular evidence for focal latent HPV infection in humans. Papillomavirus Res. 2019;7:82-7. https://doi.org/10.1016/j.pvr.2019.02.004

23. Maglennon GA, McIntosh PB, Doorbar J. Immunosuppression facilitates the reactivation of latent papillomavirus infections. J Virol. 2014;88(1):710-6. https://doi.org/10.1128/JVI.02589-13.

24. Adcock R, Cuzick J, Hunt WC McDonald RM, Wheeler CM. New Mexico HPV pap registry steering committee. Role of HPV genotype, multiple infections, and viral load on the risk of high-grade cervical neoplasia. Cancer Epidemiol
Biomark Prev. 2019;28(11):1816-24. https://doi.org/10.1158/1055-9965.EPI-190239 .

25. Chao A, Chen TC, Hsueh C, Huang CC, Yang JE, Hsueh S, et al. Human papillomavirus in vaginal intraepithelial neoplasia. Int J Cancer. 2012;131(3): E259-68. https://doi.org/10.1002/ijc.27354.

26. Zhang S, Saito M, Yamada S, Sakamoto J, Takakura M, Takagi H, et al. The prevalence of VAIN, CIN, and related HPV genotypes in Japanese women with abnormal cytology. J Med Virol. 2020;92(3):364-71. https://doi.org/10.1 002/jmv.25611.

27. Alemany L, Saunier M, Tinoco L, Quirós B, Alvarado-Cabrero I, Alejo M, et al. HPV WAP study group. Large contribution of human papillomavirus in vaginal neoplastic lesions: a worldwide study in 597 samples. Eur J Cancer. 2014;50(16):2846-54. https://doi.org/10.1016/j.ejca.2014.07.018.

\section{Publisher's Note}

Springer Nature remains neutral with regard to jurisdictional claims in published maps and institutional affiliations.
Ready to submit your research? Choose BMC and benefit from:

- fast, convenient online submission

- thorough peer review by experienced researchers in your field

- rapid publication on acceptance

- support for research data, including large and complex data types

- gold Open Access which fosters wider collaboration and increased citations

- maximum visibility for your research: over $100 \mathrm{M}$ website views per year

At $\mathrm{BMC}$, research is always in progress.

Learn more biomedcentral.com/submissions 